\title{
PERSPECTIVAS PARA A ACESSÃO DO BRASIL JUNTO À OCDE: PASSADO, PRESENTE E FUTURO
}

\section{Jaqueline de Paula Leite Zanetoni*}

RESUMO: A contribuição deste estudo foi demonstrar as perspectivas para acessão do Brasil junto à OCDE e analisar os seus impactos no direito interno. $\mathrm{O}$ artigo apresentou a dinâmica de funcionamento da Organização para posteriormente analisar a trajetória de aproximação Brasil-OCDE. Apresentou-se os impactos no direito interno desta possível acessão, tendo-se destacado a matéria tributária. Concluiu-se pela necessidade de adoção das políticas internacionais, todavia, caso todas recomendações sejam implementadas, isto resultará em profundas mudanças especialmente no sistema tributário brasileiro. $\mathrm{O}$ trabalho utilizou-se do método hipotético-dedutivo através de ferramentas de pesquisa bibliográfica e tendo como sistema de referência o Law and Economics.

Palavras-chave: Brasil. OCDE. Internacionalização da Economia. Melhores Práticas Internacionais. Impactos no Direito Interno.

\section{PERSPECTIVES FOR BRAZIL'S ACCESS TO THE OECD: PAST, PRESENT AND FUTURE}

ABSTRACT: The contribution of this study was to demonstrate the prospects for the accession of Brazil to OECD and analyze its impacts on domestic law. The article presented the Organization's operating dynamics to later analyze the trajectory of the approximation between Brazil-OECD. The impacts on domestic law were presented, fronting tax matters. It was concluded that there is a need to adopt international policies, however, if all recommendations are implemented, this will result in profound changes, especially, in the Brazilian tax system. This work used the hypothetical-deductive method through bibliographic research tools and having Law and Economics as a reference system.

Keywords: Brazil. OECD. Internationalization of the Economy. International Best Practices. Impacts on Domestic Law.

\section{INTRODUÇÃO}

Com mais de 60 anos, a Organização para Cooperação e Desenvolvimento Econômico (OCDE) representa uma das maiores e mais influentes Organizações Internacionais no cenário atual.

\footnotetext{
* Graduação em Direito pela Faculdade de Direito de São Bernardo do Campo (2011). Especialista em Direito Tributário pela Pontifícia Universidade Católica de São Paulo (2013). L.L.M em Direito Internacional Tributário pela Wirtschaftsuniversität Wien - WU (2019). Mestre em Direito pela Universidade de Marília (2020). Professora de Direito Tributário da Universidade de Mogi das Cruzes - Campus Vila Leopoldina/SP. Conselheira do Conselho Municipal de Tributos de São Paulo. Membro do corpo diretor da FEPODI. (jaquelineplzanetoni@gmail.com)
} 
De tal modo que, com vistas a oferecer um ambiente de excelência para a promoção de melhores práticas a nível global e de inovação em políticas públicas, a OCDE atua diretamente junto aos governos, formuladores de políticas (policy makers) e cidadãos de seus Estados-Membros, promovendo o desenvolvimento ${ }^{1}$ destas jurisdições. Em outras palavras, a OCDE harmoniza e desenvolve boas práticas de governança tanto no plano doméstico como no plano internacional.

Corroborando com o entendimento aqui exposto, os documentos produzidos pela OCDE em diferentes áreas deram origem à diversos instrumentos legais ${ }^{2}$ e guias gerais (guidelines) que são utilizados para a implementação de políticas públicas nacionais e resolução de problemas comuns tanto pelos Estados-Membros como pelos países parceiros da Organização.

Neste ponto, importante ressaltar que, a OCDE atua nas mais diferentes áreas, tais como: investimentos estrangeiros e multinacionais, finanças públicas e tributação ${ }^{3}$, medidas anticorrupção, meio ambiente, agricultura, turismo, educação, emprego, trabalho e assuntos sociais, saúde, seguros e previdência privada, economia digital, entre outros.

Como se assim não o fosse, a OCDE possui papel primordial junto ao G20, além de trabalhar em conjunto com as demais Organizações Internacionais. Em termos numéricos, a OCDE, além de publicar aproximadamente 250 documentos anualmente; possui cerca de 200 Comitês internos e apenas o seu Secretariado é composto por mais de 2.500 funcionários (OECD, 2020).

Paralelamente, o Brasil mantém relações com a OCDE desde meados dos anos 90 e atualmente, é o país não-membro com maior participação em instrumentos legais da OCDE.

\footnotetext{
${ }^{1} \mathrm{O}$ termo "desenvolvimento" será utilizado indistintamente, podendo representar as suas variadas dimensões, como: econômico, sustentável, financeiro. Para compreender melhor estas dimensões do desenvolvimento, eis que não serão objeto de análise neste trabalho, ver: SANTIAGO, Mariana Ribeiro; ANDRADE, Sinara Lacerda. A construção complexa do desenvolvimento: uma análise pelo prisma da teoria da complexidade, Revista Brasileira de Direito, v. 14, n. 2, 2018, pp. 180-197. Disponível em: <https://seer.imed.edu.br/index.php/revistadedireito/article/view/2667>. Acesso em: 8 fev. 2020.

${ }^{2}$ A expressão instrumentos legais será utilizada neste trabalho apenas para valer-se da nomenclatura adotada pela OCDE, a qual pode ser alvo de críticas por não perfazer um texto normativo em sentido estrito, vez que ela não é fonte estrita do chamado Direito Internacional Público. Estes instrumentos serão bem mais abordados no primeiro item deste trabalho.

${ }^{3}$ Para mais informações sobre o impacto negativo que a tributação pode acarretar às finanças públicas de um Estado, ver: RIBEIRO, Maria de Fátima. Considerações sobre as Medidas Fiscais estabelecidas para fazer frentes às crises econômicas e as repercussões no Desenvolvimento Econômico in FERREIRA, Eduardo Paz; TÔRRES, Heleno Taveira; PALMA, Clotilde Celorico (org.), Estudos em Homenagem ao Professor Doutor Alberto Xavier, Portugal: Almedina, 2013, pp. 223-250.
} 
Adicionalmente, muitas das políticas públicas adotadas pelo Brasil não se mostraram eficazes para o desenvolvimento do país e talvez por isso, a solução dos problemas econômicos, sociais e de governança internos passou a ser a adoção de uma postura baseada em parâmetros internacionais, inclusive com à possibilidade de avaliação por demais países em pé de igualdadade.

Portanto, com vistas a receber benefícios das políticas promovidas pela OCDE, especialmente da prerrogativa de atuar ativamente na criação de novos padrões internacionais, o Brasil formalizou - em 29 de maio de 2017 - o pedido de abertura de processo para acessão à Organização.

Desta forma, a partir desta pesquisa objetiva-se demostrar as perspectivas para a acessão do país junto à OCDE, e de forma mais específica, os impactos no direito interno em razão da possível entrada do Brasil nesta Organização.

Para tanto, primeiramente, será apresentado a dinâmica de funcionamento da OCDE, especialmente, no que tange: (i) as finalidades almejadas; (ii) a estrutura organizacional; (iii) os instrumentos legais; (iv) orçamento e (v) o procedimento de acessão à Estado-Membro.

Posteriormente, a trajetória de aproximação do Brasil com a OCDE e demais perspectivas serão analisadas. Finalmente, serão exibidos os potenciais impactos no direito interno da possível entrada do Brasil junto à OCDE.

Atualmente, são apontadas como possíveis barreiras para acessão do Brasil junto à OCDE, as questões relacionadas ao meio ambiente, combate à corrupção e de forma mais proeminente, as regulamentações tributárias. Portanto, a fim de delimitar o escopo destes impactos nesse trabalho, sendo a matéria tributária a mais importante e já apontada objetivamente pela OCDE como o maior entrave à acessão brasileira, esse campo será mais bem analisado no último item do presente trabalho.

Finalmente, para atingir os objetivos traçados nesse artigo, o qual foi construído sob a técnica de pesquisa bibliográfica através do método hipotético-dedutivo, e utilizando como sistema de referência o Law and Economics ${ }^{4}$.

\footnotetext{
${ }^{4}$ Para mais informações a respeito desse sistema de referência: CALIENDO, Paulo. Direito tributário e análise econômica do direito: uma visão crítica. Rio de Janeiro: Elsevier, 2008; CARVALHO, Cristiano Rosa de. Teoria do sistema jurídico: direito, economia, tributação. São Paulo: Ed. Quartier Latin, 2005.
} 


\section{UMA ANÁLISE DA DINÂMICA DE FUNCIONAMENTO DA OCDE}

Como ponto de partida, faz-se necessário mencionar que, a OCDE é uma Organização Internacional fundada pelos Estados Europeus após a Segunda Guerra Mundial (mais precisamente em 1948) com o fim específico de promover a cooperação entre os Estados-Membros ${ }^{5}$, bem como impulsionar o progresso econômico e social entre estes países em razão do Plano Marshall. ${ }^{6}$

Inicialmente denominada de Organização para a Cooperação Econômica Europeia (OCEE), recebeu a denominação atual somente após a sua reconstituição em 1960 ao incluir entre seus propósitos à assistência para os países em desenvolvimento. ${ }^{7}$

A OCDE está sediada em Paris(França) e em sua concepção moderna, pode ser classificada como um fórum único onde os Estados-Membros trabalham em conjunto para enfrentar os desafios decorrentes da globalização em todas as suas vertentes (tais como: econômico, social e ambiental), resultando na identificação de boas práticas e coordenação de políticas públicas no plano doméstico e internacional (OECD, 2008).

Todo o trabalho da OCDE é realizado através da coleta, monitoramento e análise de dados dos Estados-Membros e países parceiros a fim de prever desenvolvimentos econômicos e mudanças nos padrões adotados a nível global.

Portanto, sob o ponto de vista prático, a OCDE dedica-se à viabilização de padrões convergentes em diversas áreas consideradas relevantes para o desenvolvimento, tais como: agricultura, meio ambiente, defesa da concorrência, política tributária, investimentos, combate à corrupção, economia digital, entre outras (BRASIL, 2020).

\footnotetext{
${ }^{5}$ Para maiores informações, ver: Convention for European Economic Cooperation, 1948. Disponível em: <https://www.cvce.eu/content/publication/1999/1/1/769de8b7-fe5a-452c-b418-

09b068bd748d/publishable_en.pdf>. Acesso em: 5 mar. 2020. A Convenção foi assinada originalmente por 18 participantes (Áustria, Bélgica, Dinamarca, França, Grécia, Holanda, Irlanda, Islândia, Itália, Luxemburgo, Noruega, Portugal, Reino Unido, Suécia, Suíça, Turquia, Alemanha Ocidental (representada pelas Zonas de Ocupação francesa, americana e britânica) e a zona anglo-americana do Território Livre de Trieste.

${ }^{6}$ O Plano Marshall foi um programa de ajuda econômica promovido pelos Estados Unidos da América e endereçado à reconstrução econômica dos países da Europa Ocidental após a Segunda Guerra Mundial. Para maiores informaç̃os, ver: OECD. Historial Series. Explorations in OEEC History, edited by Richard T. Griffiths, 1997. Disponível em: <https://read.oecd-ilibrary.org/economics/explorations-in-oeechistory_9789264067974-en\#page1>. Acesso em: 5 mar. 2020.

${ }^{7}$ Os Estados-Membros originais da OCDE são: Alemanha, Áustria, Bélgica, Canadá, Dinamarca, Espanha, Estados Unidos da América, França, Grécia, Holanda, Irlanda, Islândia, Itália, Luxemburgo, Noruega, Portugal, Reino Unido, Suécia, Suíça e Turquia. OECD. Historial Series. Explorations in OEEC History, edited by Richard T. Griffiths, 1997. Disponível em: <https://read.oecd-ilibrary.org/economics/explorations-in-oeechistory_9789264067974-en\#page1>. Acesso em: 5 mar. 2020.
} 
A ampla diversidade de temas tratados somente evidencia a vasta capacidade de articulação da OCDE e a concretização de uma agenda pautada pelo desenvolvimento e crescimento dos seus Estados-Membros, além de influenciar à alocação de investimentos internacionais (OECD, 2020).Neste ponto, importante observar que, cerca de $30 \%$ de todos os instrumentos legais da OCDE tratam de questões relacionadas ao meio ambiente (FIESP, 2019).

Atualmente, a OCDE possui $36^{8}$ Estados-Membros constituídos por muitos dos principais países industrializados. Interessantemente, através desta pesquisa, restou evidenciado que desde sua criação, nenhum Estado-Membro pediu para sair da OCDE, o que demonstra o prestígio desta na promoção das suas finalidades.

Além dos Estados-Membros, desde 2014, a OCDE vem trabalhando em conjunto com alguns países parceiros ${ }^{9}$ (key partners) a fim de aproximá-los dos padrões adotados pela Organização. Tais países participam das discussões políticas realizadas nos órgãos da OCDE, bem como das pesquisas promovidas por estes e são incluídos nos dados estatísticos divulgados pela Organização.

Sob o ponto de vista prático, a incorporação de outros players junto ao palco da OCDE (ainda que de forma secundária), acaba por garantir uma maior influência desta no cenário internacional em face das demais Organizações, pois amplia sua atuação e possibilita a divulgação de suas políticas para outras jurisdições.

Corroborando com o entendimento aqui exposto, os Estados-Membros juntamente com os principais parceiros representam cerca de $80 \%$ do comércio e investimento mundial, resultando na consolidação de uma rede global das políticas e boas práticas promovidas pela Organização (OECD, 2020).

Prosseguindo, o trabalho da OCDE é realizado através da seguinte estrutura:

\footnotetext{
${ }^{8}$ São eles: Alemanha, Austrália, Áustria, Bélgica, Canadá, Chile, Coréia, Dinamarca, Eslovênia, Espanha, Estados Unidos, Estônia, Finlândia, França, Grécia, Holanda, Hungria, Irlanda, Islândia, Israel, Itália, Japão, Letônia, Luxemburgo, México, Noruega, Nova Zelândia, Peru, Polônia, Portugal, Reino Unido e República Tcheca. OECD. List of OECD Member countries - Ratification of the Convention on the OECD, 2020. Disponível em: <https://www.oecd.org/about/document/list-oecd-member-countries.htm>. Acesso em: 8 fev. 2020.

${ }^{9}$ São eles: África do Sul, Brasil, China, Índia e Indonésia. OECD. Our Global Reach, 2020. Disponível em: <https://www.oecd.org/about/members-and-partners>. Acesso em: 8 fev. 2020.
} 


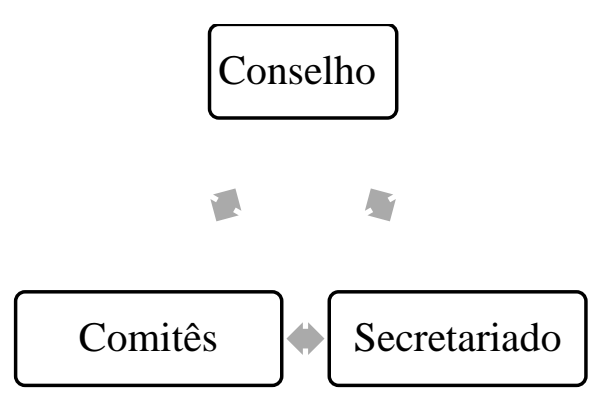

(Gráfico elaborado pela autora com base nos dados obtidos em: OECD. Organisational structure. Disponível em: <https://www.oecd.org/about/structure/>. Acesso em: 5 mar. 2020.)

Nesse esquema institucional, o Conselho é responsável pela supervisão e direção estratégica da Organização, sendo formado pelos representantes dos Estados-Membros e da Comissão Europeia ${ }^{10}$. E, via de regra, a tomada de decisões junto ao Conselho é realizada por consenso (OECD, 2020).

As diretrizes estabelecidas pelo Conselho são realizadas pelo Secretariado da OCDE quando da elaboração das propostas que serão promovidas pela Organização. Em outras palavras, o Secretariado é responsável pela análise e elaboração das propostas das políticas a serem implementadas pela OCDE, sendo formado pelo Secretário-Geral e secretarias gerais adjuntas (OECD, 2020).

Paralelamente, os Comitês ${ }^{11}$ atuam na discussão e implementação pelos EstadosMembros das políticas promovidas pela OCDE (e de forma mais específica, pelo Secretariado). Os Comitês são compostos pelos representantes dos Estados-Membros e dos países parceiros, bem como por grupos de trabalhos e órgãos de especialistas.

Portanto, a fim de tutelar os interesses por ela promovidos, a OCDE poderá: (i) editar decisões; (ii) realizar recomendações e (iii) celebrar acordos com os Estados-Membros, terceiros Estados e demais Organizações Internacionais. ${ }^{12}$ Sob o ponto de vista prático, a atuação da OCDE se dá através de 5 instrumentos legais, são eles:

10 A Comissão Europeia participa dos trabalhos da OCDE nos termos do artigo 13 da Convenção da Organização. Nesse sentido: Article 13. Representation in the Organisation of the European Communities established by the Treaties of Paris and Rome of 18th April, 1951, and 25th March, 1957, shall be as defined in Supplementary Protocol No. 1 to this Convention. OECD. Convention on the Organisation for Economic Cooperation and Development, $1960 . \quad$ Disponível em: <https://www.oecd.org/general/conventionontheorganisationforeconomicco-operationanddevelopment.htm>. Acesso em: 5 mar. 2020.

${ }^{11}$ De acordo com a OCDE: "The OECD works through more than 300 committees, expert and working groups which cover almost all areas of policy making. Our committees propose solutions, assess data and policy successes, and review policy actions among Member countries. They cover the same issue areas as government ministries, such as education, finance, trade, environment, development, and liaise with country-level experts." OECD. Organisational structure, 2020. Disponível em: <https://www.oecd.org/about/structure/>. Acesso: 5 mar. 2020.

${ }^{12}$ Nesse sentido: Article 5. In order to achieve its aims, the Organisation may: 
- Decisões: de caráter vinculante para todo os Estados-Membros;

- Recomendações: de caráter não-vinculante;

- Declarações: instrumentos solenes que estabelecem compromissos políticos e via de regra, são utilizadas nas reuniões realizadas pelo Conselho;

- Acordos Internacionais: concluídos no âmbito da Organização, gerando obrigações para as partes contratantes;

- Arranjos, entendimentos e outros: desenvolvidos apenas para uma finalidade específica e adotados somente por alguns Estados-Membros (por exemplo: o Understanding on Maritime Transport Principles, o qual dispõe acerca do entendimento internacional dos princípios marítimos).

Concluindo parcialmente, a relação entre os órgãos da OCDE; os seus instrumentos legais e a implementação das políticas promovidas pela Organização pelos Estados-Membros e países parceiros; poderá ser melhor visualizada através do fluxograma a seguir:

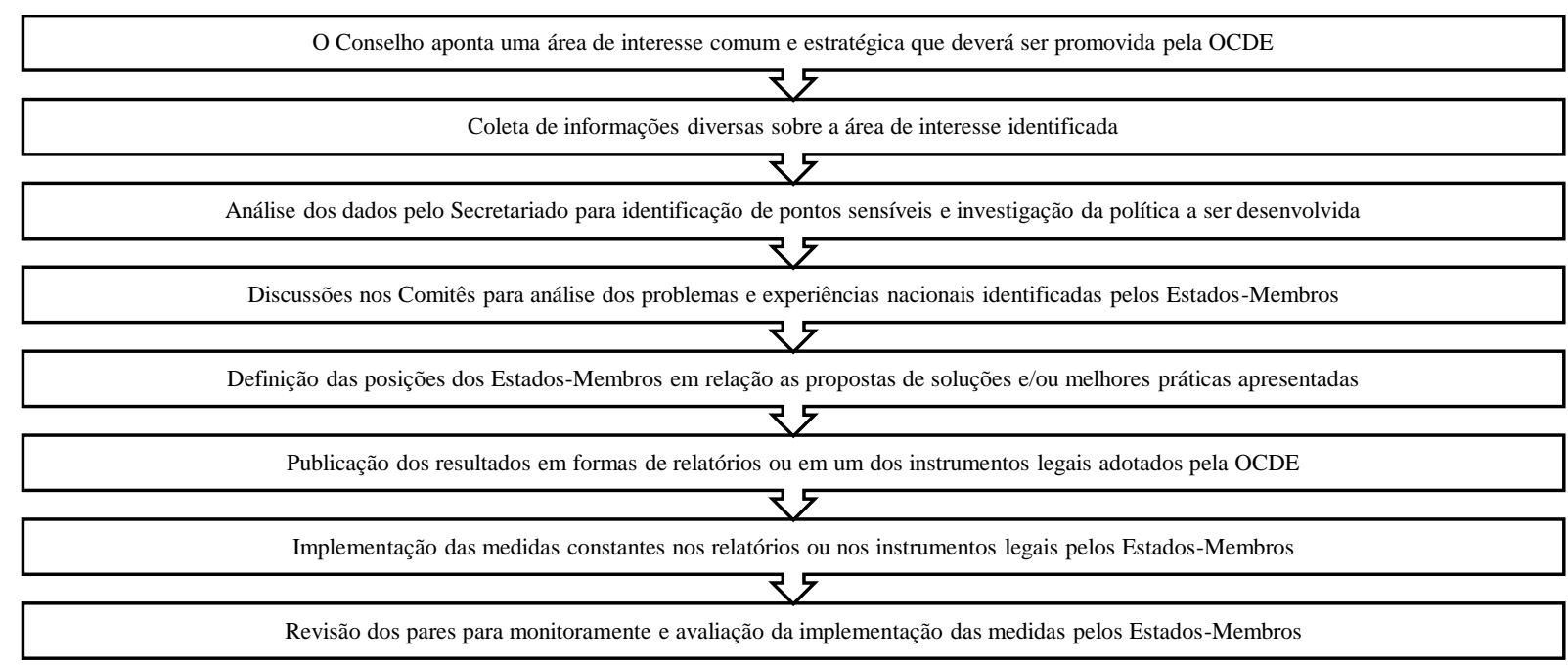

(Gráfico elaborado pela autora de acordo com as informações obtidas em OECD. Organisational structure. Disponível em: <https://www.oecd.org/about/structure/>. Acesso em: 5 mar. 2020.)

(a) take decisions which, except as otherwise provided, shall be binding on all the Members;

(b) make recommendations to Members; and

(c) enter into agreements with Members, non-member States and international organisations. OECD. Convention on the Organisation for Economic Co-operation and Development, 1960. Disponível em: <https://www.oecd.org/general/conventionontheorganisationforeconomicco-operationanddevelopment.htm>. Acesso em: 5 mar. 2020. 
Neste ponto, importante observar que, a OCDE não possui tribunais próprios e nem um órgão de solução de controvérsias ${ }^{13}$, sendo que, todos os seus instrumentos legais deverão - primeiramente - ser incorporados a nível doméstico para terem validade e, por consequência, vigência e eficácia.

Todavia, em que pese a ausência dos mecanismos de solução de controvérsias citados, a OCDE vem sendo bem-sucedida na implementação das políticas por ela promovidas, resultando em um alto índice de engajamento efetivo dos Estados-Membros no cumprimento dos seus instrumentos legais, o que pode ser atribuído à coerção moral derivada das avaliações feitas pelos pares (peer review). ${ }^{14}$

Adicionalmente, embora apenas as decisões possuam caráter vinculante; sob o ponto de vista prático, a diferença entre os três principais instrumentos legais da OCDE (decisões, recomendações e declarações) é diminuta eis que todos os Estados-Membros estão sujeitos aos controles de implementações das medidas promovidas pela Organização através das avaliações pelos pares (BRASIL, 2020).

Atualmente, a OCDE possui $254^{15}$ instrumentos legais em vigor, sendo: (i) 177 recomendações; (ii) 29 declarações; (iii) 25 decisões; (iv) 10 acordos internacionais e (v) 14 arranjos, entendimentos e outros (OECD, 2020).

Como se assim não o fosse, os documentos da OCDE são publicados nos idiomas oficiais da Organização, quais sejam, inglês e francês. E, portanto, deverão ser interpretados em sua redação original eis que qualquer tradução será imperfeita em relação aos textos originários.

Prosseguindo, todos os Estados-Membros devem pagar quotas obrigatórias para manutenção das atividades da OCDE, estas que são calculadas de acordo com o PIB de cada país (FIESP, 2019). Somente a título de esclarecimento, faz-se necessário mencionar que, os

\footnotetext{
${ }^{13}$ Em relação a (in)diferenciação funcional do Direito Internacional, vez que este não possui meios próprios para aplicar a coerção estatal e a ausência de remédio processual tutelado pelas normas internacionais, Jonathan Barros Vita dispõe: "Sintetizando, apesar de a norma internacional individual e concreta que estabelece o direito à retaliação ser internacional, sua operacionalização depende de instrumentos internos (sistema politico e jurídico internos) que se utilizam de medidas unilaterais para tanto, ainda que autorizadas no âmbito do sistema internacional, o mesmo ocorrendo com a arbitragem e o reconhecimento e enforcement de suas decisões." VITA, Jonathan Barros. Teoria Geral do Direito: Direito Internacional e Direito Tributário, São Paulo: Quartier Latin, 2011, p. 160.

${ }^{14} \mathrm{O}$ sistema de avaliação pelos pares ou peer review consiste no exame da política adotada e implementada de cada Estado-Membro pelos demais Estados-Membros que se encontram em pé de igualdade. Para maiores informações, ver: OECD. Peer Review: An OECD Tool for Co-operation and Change, 2003. Disponível em: <https://read.oecd-ilibrary.org/economics/peer-review_9789264099210-en-fr\#page2>. Acesso em: 5 mar. 2020.

${ }^{15}$ De acordo com as informações verificadas em 05 de março de 2020. Após este período, os dados aqui apresentados poderão sofrer modificações. Disponível em: <https://legalinstruments.oecd.org/en/stats〉.
} 
Estados Unidos da América (EUA) contribuem, de forma individual, com 20,5\% do orçamento da OCDE, o que demonstra a influência deste país junto à Organização. ${ }^{16}$

Os Estados-Membros também podem optar por realizar contribuições voluntárias a fim de apoiar financeiramente os resultados de um programa de trabalho específico da OCDE de acordo com seus interesses particulares.

De tal modo que, as cotas obrigatórias somadas às contribuições voluntárias formam o orçamento da OCDE. O orçamento geral consolidado da OCDE para 2019 foi de 386 milhões de euros (OECD, 2019).

Neste ponto, importante observar que, o orçamento da OCDE e seu programa de trabalho são estipulados a cada dois anos pelos Estados-Membros em um sistema baseado em resultados. Particularmente, a OCDE não concede doações ou empréstimos aos EstadosMembros ou aos países parceiros, diferenciando-se assim, do Banco Mundial e do Fundo Monetário Internacional.

Continuando, estima-se que, o processo de entrada de um país na OCDE leve em média de 2 a 3 anos, desde que o país postulante implemente as recomendações realizadas pela Organização e que todos os Estados Membros manifestem concordância com a adesão (FIESP, 2019).

Nesse sentido, o processo de acessão de um país à qualidade de Estado-Membro ocorre através do cumprimento de diversas etapas. Primeiramente, faz-se necessário que, os Estados-Membros aceitem iniciar este processo após avaliarem de forma individual e coletiva a implementação dos critérios constantes no documento intitulado Framework for the Consideration of Prospective Members. ${ }^{17}$

Secundariamente, com a aprovação dos Estados-Membros, a OCDE irá apresentar o trajeto (roadmap) que deverá ser percorrido pelo país solicitante (especialmente no que tange à análise das legislações e políticas internas que serão avaliadas pelos Comitês). Ainda, o país solicitante deverá se posicionar em relação à adoção ou não (mecanismo de reserva) de cada um dos instrumentos legais promovidos pela OCDE (atualmente: 254 instrumentos legais).

\footnotetext{
${ }^{16}$ A participação em percentual dos Estados-Membros junto ao orçamento da OCDE para 2019, encontra-se disponível em: <http://www.oecd.org/about/budget/member-countries-budget-contributions.htm>. Acesso em: 5 mar. 2020.

${ }^{17} \mathrm{O}$ documento apresenta uma tabela com os principais requisitos (substanciais e processuais) que deverão ser preenchidos pelas jurisdições que almejam o status de Estado-Membro, bem como o procedimento que deverá ser adotado pelos órgãos da OCDE ao analisar um pedido de acessão. Para mais informações, ver: OECD, Framework for the Consideration of Prospective Members, 2017. Disponível em: <http://www.oecd.org/mcm/documents/C-MIN-2017-13-EN.pdf>. Acesso em: 5 mar. 2020.
} 
Importante observar que, para aprovação do pedido de acessão, é esperada uma ampla (se não total) compatibilidade tanto das legislações como das políticas internas do país solicitante com os instrumentos legais da OCDE, eis que as reservas somente serão aceitas mediante negociação realizada em todos os Comitês, ou seja, em caráter excepcional (BRASIL, 2018). Por fim, a trajetória de aproximação do Brasil com a OCDE e demais perspectivas serão analisadas a seguir.

\section{STATUS ATUAL E PERSPECTIVAS DA RELAÇÃO DO BRASIL COM A OCDE}

Movendo-se mais especificamente, o Brasil mantém relações com a OCDE desde meados dos anos 90 segundo informações fornecidas pelo próprio governo brasileiro e a partir de então, participa dos Comitês e grupos de trabalho promovidos pela Organização (BRASIL, 2020).

Não obstante, em 2007, o Brasil foi selecionado para integrar um seleto grupo de países para iniciar o processo de engajamento com a OCDE, o qual era composto também pela África do Sul, China, Índia e Indonésia. Todavia, o fortalecimento da cooperação entre o Brasil e a OCDE, principalmente em questões tributárias, deu-se em 2010 com o ingresso brasileiro no fórum global sobre transparência e intercâmbio de informações para fins tributários (OECD, 2019).

Mais ainda, o Brasil foi alçado à categoria de parceiro-chave da OCDE em 2012 e após 3 anos, precisamente em 2015, fora assinado o acordo para o marco de cooperação Brasil-OCDE (BRASIL, 2020).

Neste ínterim, importante citar que, em 2013, o Brasil se tornou membro do projeto BEPS $^{18}$ promovido pelo G20/OCDE. Como se assim não o fosse, tem sido relatado que o Brasil desempenhou um papel crítico no desenvolvimento das iniciativas promovidas pelo

\footnotetext{
${ }^{18}$ Em relação ao projeto BEPS, Francisco Lisboa Moreia explica: "Base Erosion and Profit Shifting (BEPS), ou Erosão da Base Tributável e Transferência de Lucros", é o termo utilizado para descrever o projeto de iniciativa da OCDE (Organização para a Cooperação e Desenvolvimento Econômico) que tem por objetivo identificar estratégias de planejamento tributário abusivo, que se aproveitam de lacunas nas leis internas e nos acordos para evitar a dupla tributação, normalmente com a utilização de outras jurisdições para promover a transferência destes lucros para localidades com pouca ou nenhuma atividade real, mas que apresenta carga tributária efetiva menor que a do país onde a renda foi auferida. A principal razão para a OCDE ter assumido a tarefa ocorreu da necessidade de uma ação coordenada, para que os países não implementassem uma série de medidas unilaterais que resultariam em dupla tributação." MOREIRA, Francisco Lisboa. O Projeto de Combate à Erosão das Bases Tributárias e Movimentação de Lucros (BEPS) da OCDE e a Política Tributária Internacional Brasileira: Algumas Reflexões in ROCHA, Sergio André Rocha; TÔRRES, Heleno (coords.), Direito Tributário Internacional Homenagem ao Professor Alberto Xavier, São Paulo: Quartier Latin do Brasil, 2016, pp. 212213. Ainda, ver: OECD. What is BEPS?, 2020. Disponível em: <http://www.oecd.org/tax/beps/about/>. Acesso em: 8 fev. 2020.
} 
projeto, além de ter sido beneficiado da implementação dos padrões associados as mesmas e das análises feitas pelos pares. E desde então, o Brasil como país componente do Inclusive Framework sobre o projeto BEPS continua participando da criação de uma solução de consenso para os desafios tributários decorrentes da economia digital (OECD, 2019).

Prosseguindo, no início de 2017, assinou-se um acordo para o estabelecimento de um escritório da OCDE no Brasil e em maio do mesmo ano, o país apresentou formalmente o interesse em iniciar o processo de acessão à condição de membro pleno da Organização. Para tanto, no final de 2018, foi designado o Delegado do Brasil ${ }^{19}$ junto à OCDE em Paris (BRASIL, 2020).

De modo recente, em julho de 2019, fora instituído o Conselho para a preparação e o acompanhamento do processo de acessão do Brasil à OCDE (Conselho Brasil-OCDE).

Atualmente, o Brasil é o país não-membro com maior participação em instrumentos da OCDE, fazendo parte de $82^{20}$ dos 254 instrumentos legais da Organização e está solicitando adesão a mais 65 outros instrumentos. Como se assim não o fosse, o Brasil participa de aproximadamente 30 foros e instâncias da OCDE entre Comitês e grupos de trabalho (BRASIL, 2020).

Ocorre que, em razão do seu status atual de não-membro, a participação do Brasil como associado em um dos Comitês da OCDE, por exemplo, apresenta um custo anual aproximado - de 50 mil euros. Mais ainda, na condição de participante, o custo anual é estimado em 11 mil euros (BRASIL, 2018).

Todavia, a atuação do Brasil junto à OCDE (na qualidade de associado ou participante) se dá de forma secundária, eis que o país não possui o mesmo poder de voto e a influência dos Estados-Membros na Organização.

Paralelamente, caso o pedido de acessão brasileiro seja deferido, o país poderá atuar de forma ativa na criação de novas políticas que atendam o seu interesse enquanto país em desenvolvimento e que - de fato - levem em consideração as peculiaridades existentes em sua população e território.

\footnotetext{
${ }^{19} \mathrm{O}$ manual com as informações de base para os delegados brasileiros junto às reuniões promovidas pela OCDE encontra-se disponível em: <https://sistemas.mre.gov.br/kitweb/datafiles/Paris/fr/file/ManualInfo\%20aos\%20Delegados\%20rev\%2029ago2 018.pdf $>$. Acesso em: 5 mar. 2020.

${ }^{20}$ De acordo com as informações verificadas em 5 mar. 2020. Após este período, os dados aqui apresentados poderão sofrer modificações. Disponível em: 〈https://legalinstruments.oecd.org/en/adherences〉.
} 
Somado a isso, com a conversão das políticas internas para as melhores práticas internacionais, o Brasil tornar-se-á mais atrativo para o investimento estrangeiro eis que trará maior segurança jurídica tanto para os investidores como para às autoridades administrativas; além de facilitar a realização de negócios em seu território com a redução direta dos custos de internos de investimento e produção.

De tal modo que, as empresas nacionais também serão beneficiadas com o alinhamento às políticas internacionais, favorecendo inclusive a internacionalização destas.

Particularmente, estima-se que o processo de acessão do Brasil junto à OCDE tenha duração de 3 anos e caso o pedido brasileiro seja aprovado, o país deverá arcar com uma quota obrigatória no valor de US\$ 15 milhões ao ano para manutenção das atividades da Organização (FIESP, 2019).

Dentro deste contexto, importante destacar, a manifestação pública de apoio ao pedido de acessão do Brasil realizada pelos EUA em meados de 2019, sendo um importante passo para entrada do país junto à OCDE em razão do destaque americano na Organização. ${ }^{21}$

Como se assim não o fosse, através da presente pesquisa, fora possível traçar a evolução das adesões do Brasil aos instrumentos legais e órgãos da OCDE e os esforços políticos assumidos pelo Brasil entre 2017 e 2019 para ter seu pedido de entrada aprovado, conforme dados inseridos no gráfico abaixo.

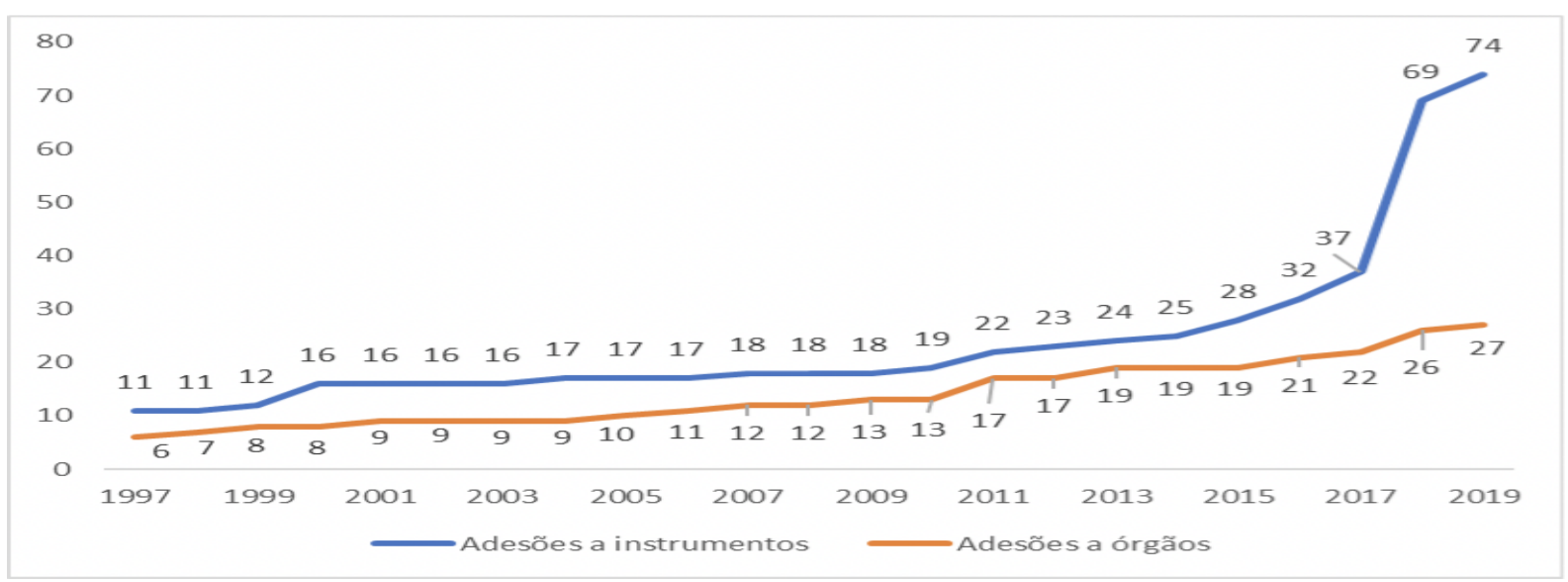

(Fonte: FIESP. Departamento de Relações Internacionais e Comércio Exterior. Análise da Acessão do Brasil à OCDE, São Paulo, 2019, p. 10. Disponivel em: <https://sitefiespstorage.blob.core.windows.net/uploads/2019/08/file-20190808135443estudoanalise-da-entrada-do-brasil-na-ocde.pdf>. Acesso em: 8 fev. 2020.)

\footnotetext{
${ }^{21}$ Somente a título informativo, até o início de 2019, os EUA apresentavam restrições à acessão do Brasil por dois motivos principais: (i) receio de prejudicar o funcionamento da OCDE em razão do aumento dos EstadosMembros e (ii) não consideravam que o Brasil apresentava a mesma inclinação ideológica dos EstadosMembros. Tal postura somente fora revista após (intensos) esforços políticos realizados pelo governo brasileiro junto aos EUA.
} 
Nesse sentido, uma análise mais detalhada destes dados se mostrou interessante a fim de mapear às áreas de concentração e direcionamento dos esforços políticos brasileiros (FIESP, 2019). Assim, verificou-se que, o Brasil já adotou:

- $50 \%$ dos instrumentos relativos ao comércio;

- $36 \%$ dos instrumentos relativos à indústria e serviços;

- $57 \%$ dos instrumentos relativos à tributação;

- $43 \%$ dos instrumentos relativos a finanças e investimentos;

- O Brasil foi o primeiro não-membro a participar do entendimento da OCDE sobre créditos de exportação para aeronaves civis.

Ocorre que, além dos esforços políticos mencionados anteriormente, o ingresso no Brasil como membro pleno da OCDE depende de seu alinhamento às diretrizes da Organização, especialmente aquelas contidas no Framework for the Consideration of Prospective Members.

Assim, de acordo com as avaliações realizadas pelo governo brasileiro, em $84 \%$ dos casos analisados, as políticas promovidas pela OCDE convergem com aquelas impulsionadas internamente, indicando que, a priori, não haveria qualquer dificuldade do Brasil em negociar as eventuais divergências identificadas (CNI, 2018).

Nesta perspectiva, já em 2017, destaca-se que o Brasil solicitou a adesão ao Código de Liberalização dos Movimentos de Capitais e ao Código de Operações Concorrentes e Intangíveis (documentos de adesão mandatória) a fim de evidenciar o empenho do país na adoção das medidas promovidas pela OCDE (CNI, 2018).

Ocorre que, um dos principais entraves para entrada do país na OCDE é a divergência protuberante em matéria tributária - o que poderá resultar em profundas mudanças no sistema tributário brasileiro em favor da OCDE, o que será mais bem abordado a seguir.

\section{OS IMPACTOS NO DIREITO INTERNO DA POSSÍVEL ENTRADA DO BRASIL NA OCDE}


Conforme mencionado anteriormente, ainda que o Brasil já tenha adotado $57 \%$ dos instrumentos relativos à tributação, a matéria tributária continua sendo o maior entrave à acessão brasileira junto à OCDE.

Tanto é que, em dezembro de 2019, a OCDE enviou - novamente - uma comissão ao país somente para discutir os padrões que deveriam ser adotados pelo Brasil relativamente as regras de preços de transferência. Sendo que, a exigência de conversão já fora apontada pela OCDE como uma condição necessária para aprovação do pedido brasileiro, ou seja, aparentemente há um veto à entrada do Brasil na Organização caso essa questão não seja solucionada, motivo pelo qual, este elemento será estudado com maior profundidade no presente item.

Nesse sentido, destaca-se a divergência das regras de preços de transferência brasileiras em relação às normas internacionalmente admitidas. Tanto é que, o Brasil ainda não solicitou adesão ao código da OCDE relativo aos preços de transferência (OECD Transfer Pricing Guidelines for Multinational Enterprises and Tax Administrations) e as recomendações relacionadas ao tema.

Dentro dos limites propostos para esta pesquisa, o relatório "Transfer Pricing in Brazil Towards Covergence with the OECD Standard" identificou as principais divergências entre o padrão Brasil e o padrão $\mathrm{OCDE}^{22}$, são elas:

- O Brasil utiliza do sistema de margens fixas para transações intercompany, não adotando (plenamente) o princípio do arm 's length. Para tanto, o relatório sugeriu como alternativa a utilização do formulary apportionment;

- A OCDE oferece 5 métodos de definição de preços de transferência para ajustes correlativos, são eles: (i) Comparable Uncontrolled Price Method (CUP); (ii) Retail Price Method (RPM); (iii) Cost Plus Method (CPM); (iv) Profit Split Method (PSM) e (v) Transactional Net Margin Method (TNMM);

\footnotetext{
${ }^{22}$ Para maiores informações no que tange às regras de preços de transferência adotadas pela OCDE e pelo Brasil, ver: OECD. Transfer Pricing in Brazil Towards Convergence with the OECD Standard, 2019. Disponível em: <https://www.oecd.org/tax/transfer-pricing/transfer-pricing-in-brazil-towards-convergence-with-the-oecdstandard.pdf $>$. Acesso em: 8 fev. 2020.
} 
- O Brasil admite apenas 3 dos 5 métodos promovidos pela OCDE em sua legislação interna. O Brasil não adota o Profit Split Method e o Transactional Net Margin Method;

- De acordo com a legislação brasileira, é possível escolher o método mais benéfico ao contribuinte (salvo transações com commodities). Em sentido contrário, pelas regras da OCDE, a escolha deverá ser realizada de acordo com o método mais adequado para a transação (most appropriate method);

- Análise de comparabilidade para a escolha dos métodos e para definição de transações que serão utilizadas como parâmetro em razão da divergência apontada no item anterior;

- O sistema de margens fixas adotado pelo Brasil não alcança com satisfação as operações envolvendo ativos intangíveis, serviços intragrupos e reestruturação de empresas. Ainda, para tais operações, os métodos mais adequados para os ajustes correlativos seriam o Profit Split Method e o Transactional Net Margin Method - não adotados pelo Brasil;

- Para solucionar as disputadas decorrentes de preços de transferência entre autoridades administrativas e contribuintes, a OCDE propõe 3 mecanismos de resolução de conflitos, são eles: procedimento amigável, Advance Pricing Agreement (APA) e arbitragem. Todavia, a arbitragem não é aplicada no âmbito tributário no Brasil.

Em suma, no que tange às regras de preços de transferência, caso todas recomendações contidas no relatório sejam adotadas internamente, pode-se dizer que isto poderá resultar no descarte total do sistema brasileiro em favor do modelo OCDE produzindo disputas tributárias de grande complexidade.

Adicionalmente, a melhoria do ambiente de negócios no Brasil está diretamente relacionada a necessidade de melhoria do sistema tributário nacional, eis que a neutralidade tributária somente poderá ser atingida com uma mudança estrutural na tributação do consumo a fim de maximizar a eficiência das empresas e minimizar as ineficiências - especialmente relacionadas aos custos de compliance e a competitividade empresarial.

Nesse sentido, o modelo brasileiro de Imposto sobre o Valor Adicionado (IVA) é subdividido em pelo menos 5 sistemas diferentes, que passam pelo nível municipal, regional e 
federal, alguns possuem sistema cumulativo e outros não-cumulativo. Portanto, a tributação indireta e sobre o consumo também poderá ser um obstáculo para a entrada do Brasil junto à OCDE.

Corroborando com o entendimento acima, essa cacofonia brasileira resulta na chamada guerra fiscal para tributar a concorrência tributária no Brasil existente entre cidades e estados - o que pode ajudar a entender os riscos que ocorrem quando os níveis subnacionais de governo buscam estratégias proativas de incentivo ao investimento, com pouca consideração pelas medidas tomadas em outras regiões e o interesse nacional mais amplo.

Particularmente, esses incentivos fiscais estaduais e municipais são calcados nos chamados tributos indiretos, algo quase inédito na prática mundial, o que gera distorções concorrenciais e gera perda da necessária neutralidade fiscal.

Ainda que a adoção de um único IVA nunca tenha sido exigência expressa da OCDE, importante observar que, no relatório econômico OCDE-Brasil publicado em 2018, a Organização apontou 4 necessidades principais para o Brasil, são elas: (i) redução do custo elevado de adaptação às complexas normas tributárias nacionais - estas que são decorrentes principalmente da tributação indireta; (ii) criação de um imposto sobre consumo nacional alinhado aos padrões internacionais; (iii) redução das barreiras de importação e (iv) cuidados para não onerar a exportação. ${ }^{23}$

Tanto é que, o assunto está cada vez mais sob os holofotes quando se fala em reforma tributária no Brasil. Corroborando com o entendimento aqui exposto, o projeto de criação de um imposto único sobre o consumo do tipo IVA denominado Imposto sobre Bens e Serviços (IBS) existente tanto na proposta de emenda constitucional encabeçada tanto pela Câmara dos Deputados (PEC n. 45/2019) quando à promovida pelo Senado Federal (PEC n. 110/2019) comumente é justificada pela necessidade de alinhamento aos padrões internacionais exigidos pela OCDE. ${ }^{24}$

Portanto, a aprovação de qualquer uma das propostas de reforma tributária aqui mencionadas irá resultar em uma modificação substancial do sistema brasileiro de tributos

\footnotetext{
${ }^{23}$ Para maiores informações, ver: OECD. Relatórios Econômicos OCDE Brasil, 2018, p. 3. Disponível em: $\langle$ http://www.oecd.org/economy/surveys/Brazil-2018-OECD-economic-survey-overview-Portuguese.pdf>. Acesso em: 8 fev. 2020.

${ }^{24}$ Para um comparativo entre os textos das propostas PEC n. 45/2019 e PEC n. 110/2019, ver: CENTRO DE CIDADANIA FISCAL. Comparação entre as propostas de reforma tributária: PEC 45, COMSEFAZ e PEC 110 (Parecer do Relator), 2019.
} 
indiretos eis que, em suma, as propostas promovem a fusão de 5 tributos incidentes sobre o consumo em apenas um imposto.

Como se assim não o fosse, eventuais mudanças nas políticas de negociação de tratados em matéria tributária adotadas pelo Brasil, também poderão gerar impactos internos, eis que o país promove à tributação na fonte dos rendimentos em detrimento do Modelo de Convenção da OCDE para evitar a dupla tributação (tributação no Estado de residência).

Neste ponto, ressalta-se que, o Brasil - via de regra - enquadra-se como um país importador de capital e, portanto, em uma operação transfronteiriça irá figurar como o Estado da fonte dos rendimentos e poderá sofrer limitações ao seu poder de tributar caso adote em sua totalidade o Modelo OCDE.

Ademais, o Brasil não adotou todas as medidas propostas pelo projeto BEPS em seus tratados em matéria tributária, especialmente no que tange a não implementação do Instrumento Multilateral (Multilateral Convention to Implement Tax Treaty Related Measures to Prevent Base Erosion and Profit Shifting) e a não adoção da arbitragem como método de solução de controvérsias.

Finalmente, os métodos para eliminar à dupla tributação adotados pelo Brasil abrangem os mecanismos de matching credit e tax sparing condenados pela OCDE. ${ }^{25} \mathrm{Em}$ outras palavras, a eliminação de tais mecanismos somada ao real alinhamento dos tratados brasileiros com o Modelo OCDE poderá gerar uma externalidade positiva, qual seja, o aumento da rede de tratados em matéria tributária brasileira com a consequente atração de investimentos estrangeiros no país.

\section{CONCLUSÃO}

A OCDE vem sendo bem-sucedida no que tange tanto à elaboração de políticas que promovam melhores práticas no cenário internacional como na implementação destas pelos Estados-Membros e países parceiros.

A estrutura da OCDE funciona como um sistema onde as atividades realizadas por todos os seus órgãos estão interligadas a fim de impulsionarem as finalidades visadas pela Organização.

\footnotetext{
${ }^{25}$ Para a definição e diferenciação dos institutos do matching credit e tax sparing, ver: TÔRRES, Heleno Taveira. Pluritributação Internacional sobre as Rendas de Empresas. São Paulo: Revista dos Tribunais. 2001.
} 
Os Estados Unidos da América é o país que mais contribui com o orçamento da OCDE e por isso, possui uma influência significativa junto à Organização.

Atualmente, o Brasil é o país não-membro com maior participação em instrumentos legais da OCDE e já adotou 57\% dos instrumentos relativos à tributação, o que demonstra o direcionamento dos esforços políticos nacionais para entrar na Organização.

Caso o pedido de acessão brasileiro seja deferido, o país poderá atuar de forma ativa na criação de novas políticas que atendam o seu interesse enquanto país em desenvolvimento.

Com a conversão das políticas internas para as melhores práticas internacionais, o Brasil tornar-se-á mais atrativo para o investimento estrangeiro, além de promover a internacionalização das empresas nacionais.

Caso todas recomendações da OCDE venham a ser adotadas internamente, isso resultará em profundas mudanças no sistema brasileiro, destacando-se a proeminência da matéria tributária, pois as regras dos preços de transferência, aparentemente, são uma condição necessária para que tal acessão ocorra.

A adoção do padrão OCDE das regras de preços de transferência pode gerar uma externalidade negativa que é a produção de disputas tributárias de grande complexidade.

A simplificação do sistema de tributos indiretos nos moldes das reformas tributárias apresentadas pode eliminar mais um entrave ao ingresso brasileiro na OCDE e aumentar as eficiências das empresas nacionais e gerar neutralidade tributária.

O alinhamento integral dos tratados brasileiros ao modelo OCDE, especialmente no campo das cláusulas de solução de controvérsias (com a adoção da arbitragem) e com a eliminação das cláusulas de matching credit e tax sparing aumentará a rede de tratados brasileira significativamente.

\section{REFERÊNCIAS}

BRASIL. Itamaraty. Brasil e a OCDE, 2020. Disponível em: <http://www.itamaraty.gov.br/pt-BR/politica-externa/diplomacia-economica-comercial-efinanceira/15584-o-brasil-e-a-ocde>. Acesso em: 8 fev. 2020.

BRASIL. Ministério das Relações Exteriores. Manual de informações de base para os delegados brasileiros às reuniões da OCDE, 2018. Disponível em: 
<https://sistemas.mre.gov.br/kitweb/datafiles/Paris/fr/file/ManualInfo\%20aos\%20Delegados \%20rev\%2029ago2018.pdf>. Acesso em: 5 mar. 2020.

CALIENDO, Paulo. Direito tributário e análise econômica do direito: uma visão crítica. Rio de Janeiro: Elsevier, 2008.

CARVAlHO, Cristiano Rosa de. Teoria do sistema jurídico: direito, economia, tributação. São Paulo: Ed. Quartier Latin, 2005.

CENTRO DE CIDADANIA FISCAL. Comparação entre as propostas de reforma tributária: PEC 45, COMSEFAZ e PEC 110 (Parecer do Relator), 2019.

CNI. Confederação Nacional da Indústria. O Brasil na OCDE: um Caminho Natural, 2018. Disponível em: <https://bucket-gw-cni-static-cmssi.s3.amazonaws.com/media/filer_public/e6/c1/e6c13ec4-0113-469e-9792753c399a1251/04_-_o_brasil_na_ocde.pdf>. Acesso em: 5 mar. 2020.

FIESP. Departamento de Relações Internacionais e Comércio Exterior. Análise da Acessão do Brasil à OCDE, São Paulo, 2019. Disponível em: $<$ https://sitefiespstorage.blob.core.windows.net/uploads/2019/08/file-20190808135443estudoanalise-da-entrada-do-brasil-na-ocde.pdf>. Acesso em: 8 fev. 2020.

MOREIRA, Francisco Lisboa. O Projeto de Combate à Erosão das Bases Tributárias e Movimentação de Lucros (BEPS) da OCDE e a Política Tributária Internacional Brasileira: Algumas Reflexões in ROCHA, Sergio André; TÔRRES, Heleno (coords.). Direito Tributário Internacional Homenagem ao Professor Alberto Xavier, São Paulo: Quartier Latin do Brasil, 2016.

OECD, Framework for the Consideration of Prospective Members, 2017. Disponível em: <http://www.oecd.org/mcm/documents/C-MIN-2017-13-EN.pdf>. Acesso em: 5 mar. 2020.

OECD. Convention on the Organisation for Economic Co-operation and Development, 1960.

Disponível em: $<$ https://www.oecd.org/general/conventionontheorganisationforeconomiccooperationanddevelopment.htm>. Acesso em: 5 mar. 2020. 
OECD. Historial Series. Explorations in OEEC History, edited by Richard T. Griffiths, 1997. Disponível em: <https://read.oecd-ilibrary.org/economics/explorations-in-oeechistory_9789264067974-en\#page1>. Acesso em: 5 mar. 2020.

OECD. How we work?, 2020. Disponível em: <http://www.oecd.org/about/how-we-work/>. Acesso em: 5 mar. 2020.

OECD. List of OECD Member countries - Ratification of the Convention on the OECD, 2020. Disponível em: <https://www.oecd.org/about/document/list-oecd-membercountries.htm>. Acesso em: 8 fev. 2020.

OECD. Member Countries' Budget Contributions for 2019. Disponível em: $<$ http://www.oecd.org/about/budget/member-countries-budget-contributions.htm>. Acesso em: 5 mar. 2020.

OECD. OECD Legal Instruments, 2020. Disponível em: <https://legalinstruments.oecd.org/en/>. Acesso em: 5 mar. 2020.

OECD. Organisational structure, 2020. Disponível em: <https://www.oecd.org/about/structure/>. Acesso em: 5 mar. 2020.

OECD. Our Global Reach, 2020. Disponível em: <https://www.oecd.org/about/membersand-partners>. Acesso em: 8 fev. 2020.

OECD. Peer Review: An OECD Tool for Co-operation and Change, 2003. Disponível em: <https://read.oecd-ilibrary.org/economics/peer-review_9789264099210-en-fr\#page2>. Acesso em: 5 mar. de 2020.

OECD. Relatórios Econômicos OCDE Brasil, 2018. Disponível em: <http://www.oecd.org/economy/surveys/Brazil-2018-OECD-economic-survey-overviewPortuguese.pdf>. Acesso em: 8 fev. 2020.

OECD. The OECD Organisation for Economic Co-operation and Development, 2008. Disponível em: < https://www.oecd.org/newsroom/34011915.pdf>. Acesso em: 5 mar. 2020. 
OECD. Transfer Pricing in Brazil Towards Convergence with the OECD Standard, 2019. Disponível em: <https://www.oecd.org/tax/transfer-pricing/transfer-pricing-in-braziltowards-convergence-with-the-oecd-standard.pdf>. Acesso em: 8 fev. 2020.

OECD. What is BEPS?, 2020. Disponível em: <http://www.oecd.org/tax/beps/about/>. Acesso em: 8 fev. 2020.

OEEC. Convention for European Economic Cooperation, 1948. Disponível em: <https://www.cvce.eu/content/publication/1999/1/1/769de8b7-fe5a-452c-b41809b068bd748d/publishable_en.pdf>. Acesso em: 5 mar. 2020.

RIBEIRO, Maria de Fátima. Considerações sobre as Medidas Fiscais estabelecidas para fazer frentes às crises econômicas e as repercussões no Desenvolvimento Econômico in FERREIRA, Eduardo Paz; TÔRRES, Heleno Taveira; PALMA, Clotilde Celorico (org.), Estudos em Homenagem ao Professor Doutor Alberto Xavier, Portugal: Almedina, 2013, pp. $223-250$.

SANTIAGO, Mariana Ribeiro; ANDRADE, Sinara Lacerda. A construção complexa do desenvolvimento: uma análise pelo prisma da teoria da complexidade, Revista Brasileira de Direito, v. 14, n. 2, 2018, pp. 180-197. Disponível em: <https://seer.imed.edu.br/index.php/revistadedireito/article/view/2667>. Acesso em: 8 fev. 2020

TÔRRES, Heleno Taveira. Pluritributação Internacional sobre as Rendas de Empresas. São Paulo: Revista dos Tribunais. 2001.

VITA, Jonathan Barros. Teoria Geral do Direito: Direito Internacional e Direito Tributário, São Paulo: Quartier Latin, 2011. 